\title{
Diagnosis of biliary varices using digital cholangioscopy
}

A 29-year-old woman with abdominal tuberculous lymphadenitis (ATL) being treated with anti-tuberculosis drugs underwent detailed investigations for a common bile duct (CBD) stricture. Contrast-enhanced computed tomography (CECT) revealed an extrahepatic portal venous obstruction (EPVO) and a cavernous transformation of the portal vein (CTPV). The EPVO was likely caused by portal vein thrombosis due to ATL-related chronic inflammation. Testing revealed a slight elevation of serum biliary enzymes, but no jaundice. CECT suggested a CTPV-related origin for the CBD stricture ( $\triangleright$ Fig. 1a, $\triangleright$ Fig. 1b), which was confirmed by endoscopic ultrasound (EUS) ( Fig. 2a); the mid to lower portion of the CBD appeared smooth on endoscopic retrograde cholangiography ( Fig.2b).

Intraductal ultrasonography (IDUS) showed that the narrowest point was externally compressed by multiple hypoe-

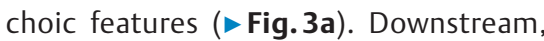
hypoechogenic features were visible inside the CBD wall ( $\triangleright$ Fig.3b; arrow). These findings were suggestive of paracholedochal and epicholedochal biliary varices.

Digital cholangioscopy (Spyglass DS; Boston Scientific, Marlborough, Massachusetts, United States) showed normal mucosa in the upper CBD and confirmed compression of the CBD midportion by biliary varices. The CBD mucosa showed hyperemia with sporadic red spots and telangiectasia ( $\mathbf{F i g . 4 a , \quad \triangleright F i g . 4 b ; ~}$ heads). Biliary varices were also detected in the CBD lumen, consistent with the hypoechogenic features observed on IDUS ( $\triangleright$ Fig.5). Interestingly, the varices were reducible by water conveyance ( $\vee$ Video 1 ). We determined that the stricture was caused by biliary varices.

Despite bleeding from the biliary mucosa during biopsy, spontaneous hemostasis was achieved. We followed-up on the CBD stricture because the patient did not have obstructive jaundice.
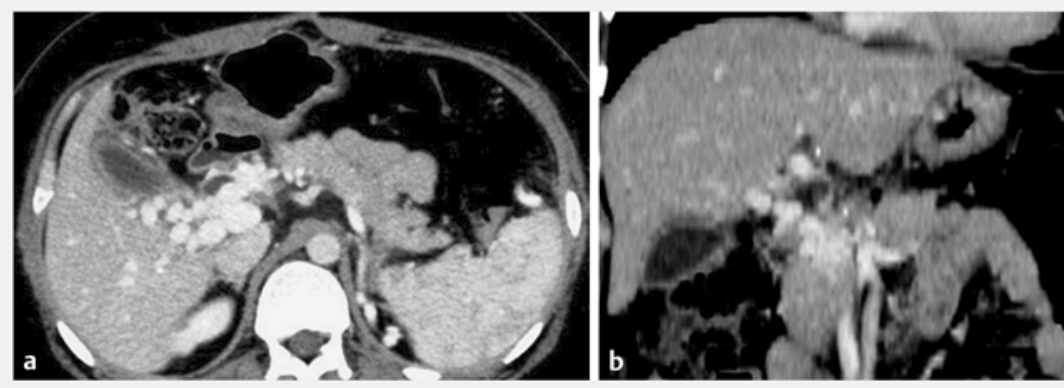

- Fig. 1 a, b Contrast-enhanced computed tomography showing the common bile duct stricture caused by cavernous transformation of the portal vein.
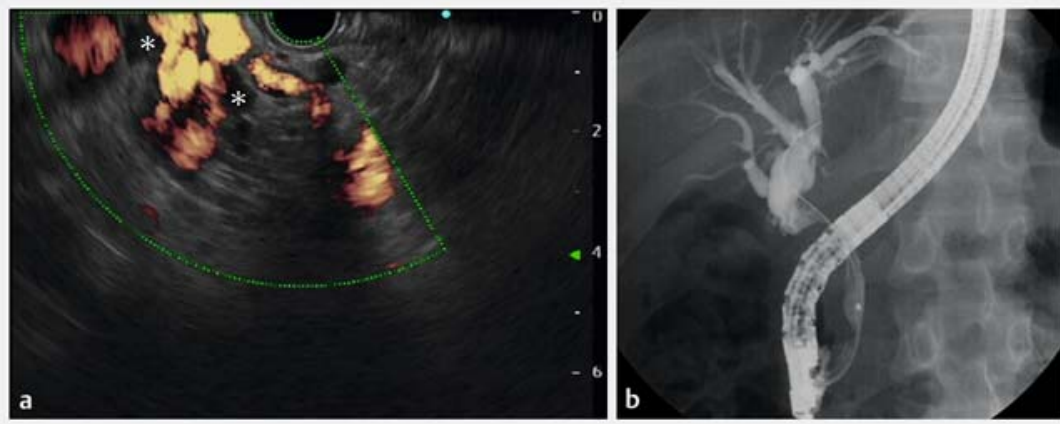

- Fig. 2 a Endoscopic ultrasound showing the common bile duct (CBD) stricture caused by cavernous transformation of the portal vein (CBD: asterisk). b Endoscopic retrograde cholangiography showing the CBD stricture, which was smooth from the mid to the lower portion of the duct.
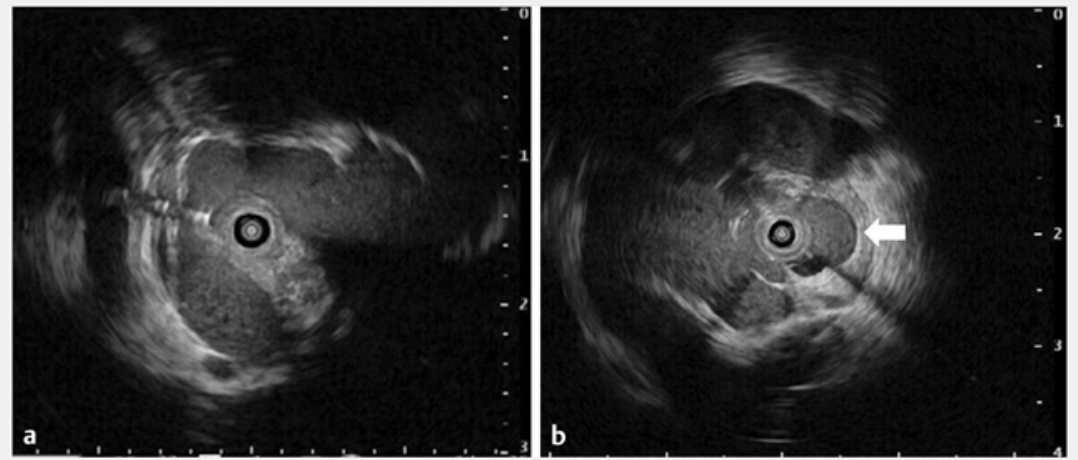

- Fig. 3 a Intraductal ultrasound image showing the narrowest point of the common bile duct (CBD) surrounded by the cavernous transformation of the portal vein outside the CBD wall. b Hypoechogenic features (arrow) inside the CBD wall. 

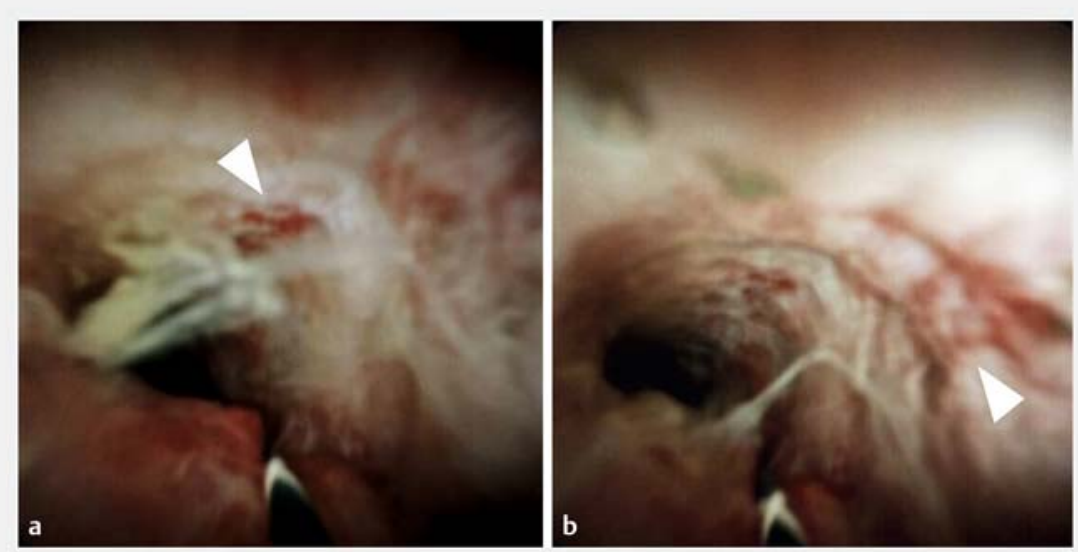

- Fig. 4 a, b Sporadic red spots and telangiectasia (arrowheads) in the common bile duct mucosa.

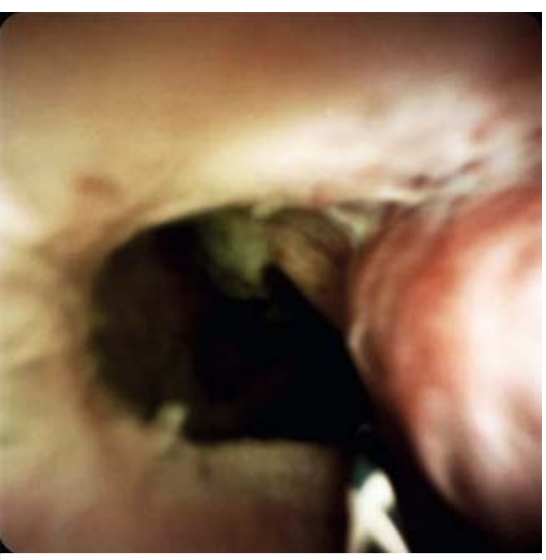

Fig. 5 Biliary varix detected in the common bile duct lumen.
Biliary varices are related to portal hypertension, primarily EPVO [1]. EUS [2] and IDUS [3] are useful tools for diagnosing biliary varices.

Although few reports describe cholangioscopic observations of biliary varices in detail $[4,5]$, we suggest that cholangioscopy is useful to diagnose biliary varices.

\section{Competing interests}

The authors declare that they have no conflict of interest.

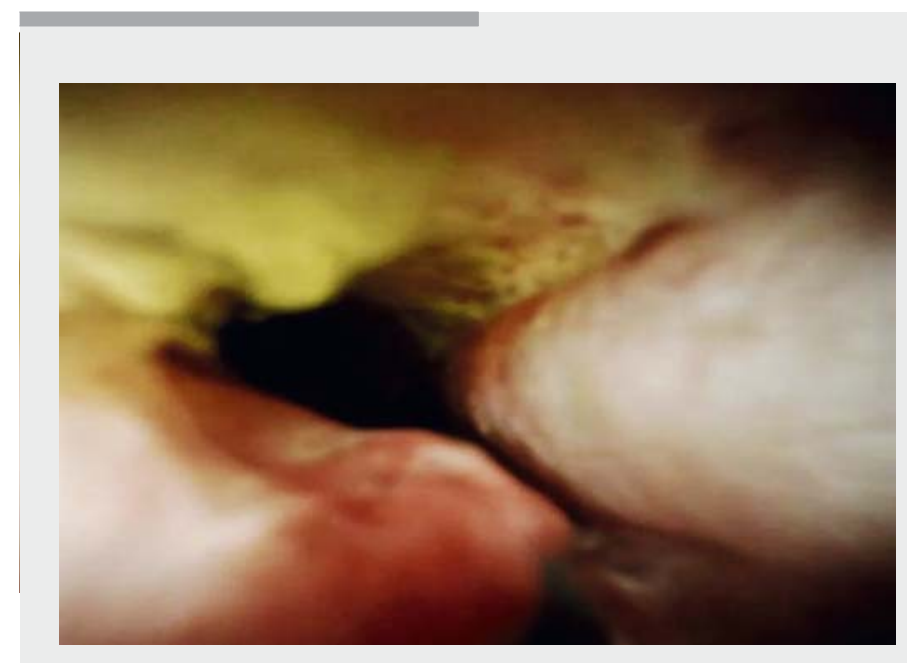

Video 1 Digital cholangioscopy of a patient with common bile duct (CBD) stricture shows a biliary varix and hyperemia of the CBD mucosa.
The authors

Tsuyoshi Suda, Tomohide Omizo, Ryota Yoshida, Takuya Seike, Naoki Oishi, Eiki Matsushita

Department of Gastroenterology, Kanazawa Municipal Hospital, Kanazawa, Ishikawa, Japan.

Corresponding author

\section{Tsuyoshi Suda, MD}

Department of Gastroenterology, Kanazawa Municipal Hospital, 3-7-3, Heiwamachi, Kanazawa, Ishikawa 921-8105, Japan Fax: +81762452690

t.suda1112@gmail.com

\section{References}

[1] Dhiman RK, Behera A, Chawla YK et al. Portal hypertensive biliopathy. Gut 2007; 56: 1001-1008

[2] Palazzo L, Hochain P, Helmer C et al. Biliary varices on endoscopic ultrasonography: clinical presentation and outcome. Endoscopy 2000; 32: 520-524

[3] Takagi T, Irisawa A, Shibukawa G et al. Intraductal ultrasonographic anatomy of biliary varices in patients with portal hypertension. Endosc Ultrasound 2015; 4: 44-51

[4] Zulli C, Sica M, Caruso A et al. A rare case of biliary tract stenosis caused by intraductal varices diagnosed by single-operator peroral cholangioscopy. Gastrointest Endosc 2016; 84: 1052-1053

[5] Phan VA, Abu-Assi R, Nguyen N. Gastrointestinal utility of per-oral cholangioscopy in the diagnosis of portal hypertension associated biliopathy. J Gastroenterol Hepatol 2016; 31: 1798

\section{Bibliography}

DOI http://dx.doi.org/10.1055/a-1236-3421

Endoscopy International Open 2020; 08: E1437E1438

Georg Thieme Verlag KG

Rüdigerstraße 14,

70469 Stuttgart, Germany

eISSN 2196-9736

(C) 2020. The Author(s).

This is an open access article published by Thieme under the terms of the Creative Commons Attribution-NonDerivative-NonCommercial License, permitting copying and reproduction so long as the original work is given appropriate credit. Contents may not be used for commecial purposes, or adapted, remixed, transformed or built upon. (https://creativecommons.org/licenses/by-nc-nd/4.0/)

\section{(ㄷ) (i) $(5)$}

